\title{
Evaluating Alfalfa (Medicago sativa L.) Cultivars for Salt Tolerance Using Laboratory, Greenhouse and Field Methods
}

\author{
John Derek Scasta (Corresponding author) \\ Natural Resource Ecology and Management, Oklahoma State University \\ 0082 Agricultural Hall, Stillwater, OK 74075, USA \\ Tel: 1-903-467-4168Ｅ-mail: scasta@okstate.edu
}

Calvin L. Trostle

Associate Professor and Extension Agronomist, Texas A\&M University 1102 East FM 1294, Lubbock, TX 79403, USA

Tel: 1-806-746-6101Ｅ-mail: c-trostle@tamu.edu

\author{
Mike A. Foster \\ Research Scientist and Station Director, Texas A\&M University (Retired) \\ 947 West I20, Pecos, TX 79772, USA
}

Tel: 1-432-448-1495 E-mail: mike.foster64@gmail.com

$\begin{array}{lc}\text { Received: January 30, } 2012 & \text { Accepted: February 14, } 2012 \quad \text { Online Published: April 17, } 2012 \\ \text { doi:10.5539/jas.v4n6p90 } & \text { URL: http://dx.doi.org/10.5539/jas.v4n6p90 }\end{array}$

This project was supported by a Texas Department of Agriculture grant. The corresponding author was a Texas Tech University graduate student at the time research was conducted.

\begin{abstract}
Salinity is a limiting factor in irrigated alfalfa (Medicago sativa L.) production in many regions of the world. Objectives of this project were to evaluate twelve alfalfa cultivar responsesto salinity using laboratory, greenhouse and field experiments. The laboratory experiment evaluated plant germination under increasing levels of salt concentration ( 0 to $2 \%$ ) and statistical differences were observed at $1.0 \%, 1.5 \%$ and $2.0 \%$ concentrations (10 $000 \mathrm{ppm}$ to $20000 \mathrm{ppm})$. The greenhouse experiment evaluated forage production of cultivars using Salt Control Ratio (SCR) values using $3840 \mathrm{ppm}$ irrigation water and significant differences were found between cultivars. The field experiment evaluated forage production under saline field conditions west of Pecos, TX (soil salinity $2131 \mathrm{ppm}$, water salinity $2950 \mathrm{ppm}$ ) with significant differences between cultivar yields. Canonical Correspondence Analysis (CCA), a constrained ordination technique,revealed statistical significance of canonical axes in explaining variation between alfalfa cultivars and laboratory, greenhouse and field experiments.
\end{abstract}

Keywords: Alfalfa, Salt, Salinity, Forage, Legume

\section{Introduction}

Soil salinity is an issue that affects an estimated 6\% of the world's land surface area or 12780 million hectares (Mha) and secondary salinization from irrigation impacts an estimated $20 \%$ of irrigated land or 1474 Mha (Chinnusamy, et al., 2005; Munns, 2011). Salinity is a complex issue to characterize due to the many factors that influence a plant's response to salinity, including: plant, soil, water, environmental and cultural factors (Maas, 1987). Soil salinity has been characterized as one of the most variable properties of soils (Miyamoto, 1988). Additionally, salinity can have different effects on a plant depending on the stage of development of the plant (Bernstein and Hayward, 1957). Salt tolerance evaluation in greenhouse environments may not correlate with field evaluations (Cluff, 1997). Thus, valid field experiments may have difficulty accurately reflecting the 
combination of these parameters (McKimmie and Dobrenz, 1987). Salinity problems are very similar to drought or water stress because salinity affects water availability causing "physiological drought". This is a function of osmotic potential decreasing as soil solution salinity levels increase resulting in decreasing soil water potential and water availability along the soil water gradient (Havlin, et al., 1999). The effects of salinity can hamper plant germination, and reduce plant growth and establishment which can result in lowered yields or a complete loss of crop (Rhoades and Loveday, 1990). Ion toxicity attributed to sodium $\left(\mathrm{Na}^{+}\right)$and chloride $\left(\mathrm{Cl}^{-}\right)$can also occur (Green, 1999). As salinity levels in the root zone increase, water becomes less likely to enter the root and at times may be pulled out of the roots (Provin and Pitt, 2001).

Alfalfa (Medicago sativa L.), is a perennial warm-season legume, that is grown on 30 Mha worldwide. Primary regions of production include the United States, Canada, Italy, France, China, south Russia, Argentina, Chile, South Africa, Australia and New Zealand (Yuegao and Cash, 2009). Alfalfa is highly sought after for its ability to produce forage that is high in crude protein and total digestible nutrients (Barnes, et al., 1980). In the United States, more than 90 percent of alfalfa grown in the 11 western states is irrigated (Hanson et al. 2008). Alfalfa has been characterized as moderately sensitive to salts with an electrical conductivity (EC) of $2.0 \mathrm{dS} / \mathrm{m} \mathrm{(1280}$ $\mathrm{ppm})$ and a threshold of $1.5 \mathrm{bars}(1 \mathrm{bar}=0.987$ atmospheres $)$ osmotic potential of soil solution at field capacity (Maas and Hoffman, 1977). An additional 7\% decrease in alfalfa yields can be expected with each $\mathrm{dS} / \mathrm{m}$ increase in saturation extract salinity (Rawlins 1979). In contrast, alfalfa has also been characterized as tolerant to salts with a range of EC values from 6.0 to 8.0 (3840 to $5120 \mathrm{ppm})$ at which some reduction in growth and yields can be expected (Longenecker and Lyerly 1974).

A recent study compared alfalfa to 4 other crops: saltbush (Atriplex spp.), balansa clover (Trifolium michelianum), subclover (Trifolium subterraneum) and tall wheatgrass (Thinopyrum ponticum), and described alfalfa as a more salt tolerant crop (Munns, 2005). Alfalfa was as tolerant as barley (Hordeum vulgare) and cotton (Gossypium spp.), however the growth of alfalfa was still retarded in saline conditions (Munns, 2005). When soils and water are both saline, it is necessary to irrigate about every other day for 6 or 7 days until alfalfa germinates and then withhold irrigation water until seedlings have several leaves or are two inches tall (Lindsey, et al., 1970). Moderate yield reductions have been observed in alfalfa crops and other forages grown with irrigation waters of EC 3 to 5 (1920 to $3200 \mathrm{ppm}$ ) (Miyamoto et al. 1984). The rate and final emergence of alfalfa cultivars declined when salinity of irrigation exceeded an EC of $4.3(2752 \mathrm{ppm})$, even though the seed germinated well in saline solutions of EC $=28$ or $17920 \mathrm{ppm}$ (Assadian and Miyamoto, 1987). Alfalfa plants that were sub-irrigated with $5000 \mathrm{ppm}(\mathrm{EC}=7.8)$ water had deformed cotyledons and were more chlorotic than were control plants (Johnson, 1989). Alfalfa can be established with minimal salt injury at levels up to EC $=4.0$ (2560 ppm equivalent) when seeded approximately $10 \mathrm{~mm}$ deep (Assadian and Miyamoto, 1987).

Describing salt tolerance in alfalfa (particularly at the germination stage) has proven to be difficult due to the differences in response to salinity at different growth stages, and the specific mechanisms of tolerance to salinity that are used by alfalfa are unknown (Smith, 1998). Alfalfa plants utilize salt exclusion as a mechanism to cope with salinity issues and they do exclude $\mathrm{Na}+$ but do not exclude Cl- (Brown and Hayward, 1956; Lauchli, 1984). Alfalfa is more salt tolerant because it is able to regulate the uptake and translocation of $\mathrm{Na}^{+}$and $\mathrm{Cl}^{-}$to prevent excessive accumulation of these ions in leaves (Munns, 2005).

Legumes, such as alfalfa, have great genetic variability which emphasizes the importance of analyzing cultivars. Germination rates are influenced by varieties and $\mathrm{NaCl}$ levels (Hefny and Dolinski, 1998). Significant differences among cultivars have been observed for ability to germinate under salt stress and subsequent selection of a cultivar (Ladak 65) at $1.75 \% \mathrm{NaCl}$ in an agar medium resulted in a 3.75 fold increase in germination at that salt concentration (Carlson, et al., 1983). Cell culture techniques have been used to select a salt tolerant alfalfa line (W75RS) that was not affected by a salt level of $62.5 \mathrm{mM}(40,000 \mathrm{ppm}$ equivalent) in nutrient solution regardless of whether callus cultures or whole plants were examined (Croughan, et al., 1978; Smith and McComb, 1981). Regeneration buds in highly saline solution revealed one somaclone (6R2IV) to have increased salt tolerance compared to the parent line and multiple copies of the pA9 gene versus single copies in the parent line (Safarenjad, et al., 1996). This evidence indicates that salinity problems can potentially be remedied through the selection of more tolerant cultivars.

Significant differences in water use efficiency were shown between alfalfa cultivars (higher transpiration efficiency of Zhongmu No. 1 and Qinglai cultivars as compared to lower transpiration efficiency of Aohan and Shouling cultivars, $p<0.01$ ) and may have potential in dealing with water shortage issues in the future ( $\mathrm{Li}$ and Zhang, 2004). Research on the trait for high fibrous rooting characteristics in alfalfa has shown some potential in usefulness as a salinity stress avoidance mechanism (Vaughan, et al., 2002). The popularity of biotechnology has been investigated as a means to improve salinity tolerance in alfalfa but none have been successful (Smith and 
Dobrenz, 1987).

The primary objective of this project was to quantify salt tolerance of 12 alfalfa cultivars at the germination level using laboratory procedures, compare its ability to produce under non-saline and repeated saline exposure levels using greenhouse methods and under saline field conditions (Table 1). Standard or localized cultivars were used for checks when appropriate and experiments were compared using multiple regression and multivariate techniques.

\section{Materials and Methods}

\subsection{Laboratory Evaluation Methods}

A laboratory experiment to assess germination of alfalfa seed was conducted following a modified version of the North American Alfalfa Improvement Conference (NAAIC) protocol, "Salt Tolerance of Germinating Alfalfa Seeds" (Rumbaugh, 1991). Twenty-five seeds from twelve alfalfa cultivars were placed in 100-mm Petri dishes under five concentrations of $\mathrm{NaCl}[0.0 \%, 0.5 \%, 1.0 \%, 1.5 \%$, and $2.0 \%$ (wt $/ \mathrm{wt}$ ) equivalent to $0 \mathrm{ppm}, 5000 \mathrm{ppm}$, $10000 \mathrm{ppm}, 15000 \mathrm{ppm}$ and $20000 \mathrm{ppm}$ dissolved salts] in de-ionized water. Four additional cultivars were evaluated as standard 'tolerant' or 'susceptible' checks (Rumbaugh, 1991). Each dish contained $4.5 \mathrm{~mL}$ of the appropriate salt solution that was applied only once at the initiation of the trial. Each dish was sprayed with Thiram fungicide and sealed with parrafilm to prevent moisture loss. One piece of Whatman \#2 filter paper was placed in the bottom of each dish with seed placed on top. Each cultivar was replicated twice per salt concentration $(n=160)$ in a randomized complete block design (RCBD) (Rumbaugh, 1991). Dishes were placed on a lab bench under dark conditions, temperature was maintained at $25^{\circ} \mathrm{C}$ and seeds were evaluated 1 week after the experiment was initiated. Seeds were recorded as either germinated or non-germinated and data were converted to mean percent germination. The $0 \%$ salt solution provided the means for a seed viability test and no significant differences occurred at that level $(p<0.05)$. An IC(50) value was then calculated to describe the osmotic potential required to inhibit germination of $50 \%$ of seeds.

\subsection{Greenhouse Evaluation Methods}

A greenhouse experiment was conducted following the NAAIC protocol, "Forage Production under Salt Stress" (Smith 1991). The same 12 cultivars evaluated in the laboratory experiment, were each planted in $3.8 \mathrm{~cm} \times 20.9$ $\mathrm{cm}$ containers (Falcon SC-10 Supercell) packed with Metro Mix 200 growth medium (3 to 5 seeds each), covered with $10 \mathrm{~mm}$ sand and thinned to 1 seedling after 14 days. All containers were irrigated for the first 14 days with $0.25 \mathrm{X}$ Hoagland's standard solution to ensure plant establishment (California Fertilizer Association, 1985). After day 14, the containers for each cultivar were divided into 1) non-saline irrigation treatment of Hoagland's solution, and 2) Hoagland's solution and $3.5 \mathrm{~g} / \mathrm{L} \mathrm{NaCl}$ (equivalent to $60 \mathrm{mM}$ or $3840 \mathrm{ppm}$ ), and containers were watered as needed throughout the experiment (Smith, 1991). Herbage was harvested $(3 \mathrm{~cm}$ above the soil surface) at 50 days after planting (DAP) (Cut 1) and discarded. Herbage was then harvested at 30-day intervals and fresh forage weight recorded for this and two subsequent harvests (final cut at 110 days). The study was replicated spatially twice with 28 containers per cultivar per replication per treatment (non-saline $(n=784)$ and saline $(n=784)$ in a completely randomized design and replicated temporally with the three harvest dates. Two test cultivars were also screened as the control population ('tolerant' AZ-90NDC-ST; 'susceptible' AZ-88NDC) (Smith, 1991) for a total of 14 cultivars in this experiment.

\subsection{Field Evaluation Methods}

\subsubsection{Research Site}

The third experiment evaluated forage production under saline field conditions at the Texas AgriLife Research Station west of Pecos, TX. The average temperature at the research station is $8^{\circ} \mathrm{C}$ in winter and the average daily minimum $-2^{\circ} \mathrm{C}$. The average temperature is $28^{\circ} \mathrm{C}$ in summer, and the average maximum is $37^{\circ} \mathrm{C}$. Annual precipitation averages $218 \mathrm{~mm}$ with $70 \%$ occurring from April through September. The soil is a Hoban silty clay loam and 2007 soil test data averages from research plots included: $\mathrm{pH}, 8.9$; sodium, 1,491 ppm; soil salinity, $3.33 \mathrm{mmhos} / \mathrm{cm}$ (1:1 saturated paste extract equivalent, equal to EC 3.33) and Sodium Adsorption Ratio (SAR) was 13.6. These values classify this soil as a sodic soil (electrical conductivity $<4.0 \mathrm{dS} / \mathrm{m}, \mathrm{pH}>8.5$ and $S A R>13$ ) (Waskom, et al., 2007; Havlin, et al., 1999). Approximately $90 \%$ of yield production potential could be realized with the given electrical conductivity levels (estimated 90\% potential at 3.4 EC) (Fipps, 2003). Statistical analysis of the field plot salinity values showed no statistical differences across the field or block $(p<0.05)$ prior to the initiation of the irrigation field study. Soil samples from plots were collected after three years to assess changes in soil salinity. 


\subsubsection{Agronomic Methods}

All 12 alfalfa cultivars were planted in a laser leveled bay in a randomized complete block design with four replications $(n=48)$. Plots were hand sown with a single-row garden seeder on October 5, 2006 at a seeding rate of 36 pounds of seed per acre with 8 rows per plot. Plot size was 1.82 meters by 6.10 meters $\left(67.7 \mathrm{~m}^{2}\right)$ with 0.91 meter alleys between replications. A 2.4 meter border was planted around the plots to prevent any border effect. Plots were flood irrigated at approximately 14 day intervals (immediately following a harvest and 14 days later). Approximately 4.5 inches was applied at each flood irrigation. Results from water analyses in 2007 (including criteria, units and limitation ratings) included: total dissolved salts (TDS), $2950 \mathrm{ppm}$ [very limiting]; conductivity, $4060 \mu \mathrm{mhos} / \mathrm{cm}$ [very limiting]; sodium absorption ratio (SAR), 11.7 [limiting]; pH, 7.10 [acceptable]; sodium $\left(\mathrm{Na}^{+}\right), 702 \mathrm{ppm}$ [very limiting; and chloride $\left(\mathrm{Cl}^{-}\right), 938 \mathrm{ppm}$ [very limiting]. The total dissolved salts and conductivity values categorize this irrigation water as Class 5: Unsuitable ( $>2100$ ppm or $>3000 \mu \mathrm{mhos}(\mathrm{cm})$ which will necessitate good drainage with the potential for sensitive plants having difficulty establishing a stand (Fipps, 2003; Provin and Pitt, 2002). The field trial was evaluated for the 2007, 2008 and 2009 growing seasons. Plots were cut at 10 centimeter height at 28-day intervals using a pull-type swather, and fresh forage weights recorded in the field immediately following harvest. Fresh forage weights were used for analyses but subsamples $(n=951)$ from each plot were collected, weighed and air dried to calculate percent dry matter and relate production information to growers. The only fertilizer application determined by soil testing was 20 pounds per acre of $\mathrm{P}_{2} \mathrm{O}_{5}$ which was applied December of 2007. Composite soil samples from each field plot $(n=48)$ were collected in February 2007 before irrigation began and again in April 2010 after three years of flood irrigation to assess changes in soil salinity levels. A summary of soil or water quality for all three experiments are presented for comparative purposes (Table 2).

\subsection{Statistical Methods}

\subsubsection{Laboratory Experiment Statistical Methods}

Laboratory statistical methods included the calculation of the mean percent germination for each salt concentration level which were subjected to one-way analysis of variance (ANOVA) $(\alpha=0.05)$, using SAS Enterprise Guide 4.3.0.10196 using the Levene's test for equal variance and Fisher's least significant-difference test (Der and Everitt, 2007). Mean percent germination values were used to develop an IC (50) value which is used to describe the osmotic potential required to inhibit germination of $50 \%$ of viable seeds. This was accomplished by converting salt concentrations to reflect osmotic potential in the unit of megapascals (MPa) according to the NAAIC procedure (Rumbaugh, 1991). The corresponding osmotic potential values were then graphed on the $\mathrm{x}$-axis with the average percent germination on the $\mathrm{y}$-axis for each cultivar and linear regression modeling was used to fit a trendline and slope equation was calculated. The IC(50) value was then calculated using the slope equation and the following equation (where $\mathrm{b}$ is the $\mathrm{y}$-intercept and $\mathrm{a}$ is the slope):

$$
I C(50)=(0.5-b) / a
$$

\subsubsection{Greenhouse Experiment Statistical Methods}

Greenhouse statistical methods included assessing forage production under saline stress as mean fresh weight herbage produced with saline irrigation as a percentage of that produced under non-saline conditions. The corresponding value was derived by comparing the production values of the salt set divided by the control set which yields the Salt Control Ratio (SCR).

$$
\text { SCR }=\text { Saline Yields } / \text { Non-Saline Yields }
$$

SCR values were then subjected to ANOVA $(\alpha=0.05)$, using SAS Enterprise Guide 4.3.0.10196 using the Levene's test for equal variance and Fisher's least significant-difference test (Der and Everitt 2007). A t-test for paired sample means was also applied in Microsoft Excel 2010 Data Analysis Tool Pack that calculated Pearson Correlation, $t$ statistic and one and two tail $p$-values to compare yields under saline and non-saline irrigation treatments.

\subsubsection{Field Experiment Statistical Methods}

Field statistical methods used the average fresh forage weight per cut over the three year period adjusted to kilograms per hectare (kg/ha) for each cultivar and submitted to ANOVA using SAS 9.2 TS Level 2M3 (Der and Everitt 2008). Analysis used the general linear model (GLM) for repeated measures to account for the randomized complete block design $(\alpha=0.05)$ and t-tests for least significant differences were assessed between cultivars. A t-test for paired sample means was used to calculate Pearson Correlation, $\mathrm{t}$ statistic and one and two tail p-values to compare yields to assess changes in soil salinity before and after the three years of irrigation in the field experiment. 


\subsubsection{Comparison of Experiment Statistical Methods}

Given the complex nature of salinity and variable responses of plants to salt stress depending on physiological and phenological factors we used multiple regression and multivariate techniques to compare experiments. Cultivars were first ranked using the rank and percentile function in Microsoft Excel 2010 Data Analysis tool pack. Multiple regression was then applied using Microsoft Excel 2010 to compare experiments. The fresh forage weights in $\mathrm{kg} / \mathrm{ha}$ were used as the dependent variable and germination rates for all 5 salinity concentrations, IC (50) values, SCR values, yields under saline irrigation in the greenhouse and yields under non-saline irrigation in the greenhouse were used as independent variables. All data was standardized (subtract mean and divide by standard deviation) to account for different measurement units (Equation 3) (Palmer, 2012).

$$
x_{\text {new }}=(x-\mu) / \sigma
$$

Bonferroni correction was applied to account for the problem of multiple comparisons. Ordination techniques were applied using CANOCO 4.5 and CANODraw to further elucidate an understanding of alfalfa salt tolerance (ter Braak and Smilauer, 2002). Ordination techniques are more common in community ecology to assess species abundances in response to environmental variables. Given the genetic variability of alfalfa and the multiple measurements of salinity tolerance we chose to apply ordination methods to assist in explaining the variance associated with salinity tolerance measure at different physiological and phenological stages. Canonical Correspondence Analysis (CCA), an unimodal response technique of direct gradient analysis that relies on weighted averaging, was conducted using field yields and data from laboratory and greenhouse experiments as explanatory variables. This method of constrained analysis allows for the identification of ordination axes based on known explanatory variables and allows for interpreting variation (ter Braak, 1986). Scaling was focused on inter-sample distances using Hill's scaling and values were square root transformed. We used a Monte-Carlo permutation test (999 permutations) under a reduced model to test the first ordination axis and all canonical axes together for statistical significance at $\alpha=0.05$. A biplot was developed using sample scores (cultivar yields) and explanatory variables. An attribute plot was also developed using greenhouse SCR values using the Loess smoother and sample scores (cultivars).

\section{Results and Discussion}

\subsection{Laboratory Results}

The $0.0 \%$ ( 0 ppm dissolved salts) screening served as the seed viability test and set the benchmark for further screening. The mean percent germination for all cultivars was $93 \% \pm 1.3$ and there were no significant differences in germination among cultivars at the seven day evaluation $(p=0.49)$. At the $0.5 \%(5000 \mathrm{ppm})$ screening the mean percent germination for all cultivars was $91 \% \pm 2.4$ and there were no significant differences between cultivar germination rates $(p=0.06)$.

At salinity concentrations of 1.0 to $2.0 \%$ significant differences among cultivars due to salinity became more pronounced. At $1.0 \%$ (10 $000 \mathrm{ppm}$ ) the mean percent germination was $88 \% \pm 4.7$ and ranged from $22 \%$ to $100 \%$ with the susceptible check (Rambler) having the lowest germination rate and significant differences were shown to occur $(p=0.005, L S D=23 \%)$ (Table 4, Figure 1). At 1.5\% (15000 ppm) the mean percent germination was $78 \% \pm 5.3$ and ranged from $2 \%$ to $96 \%$ with the susceptible check again having the lowest value. Significant differences were shown $(p=0.000, L S D=22 \%)$ (Table 4). At 2.0\% (20 $000 \mathrm{ppm})$ the mean percent germination was $31 \% \pm 5.1$ with a range from $0 \%$ to $86 \%$ and differences were significant $(p=0.009, L S D=31 \%$ ) (Table 4 ). Salado had significantly higher mean percentage germination than all other cultivars at the $2.0 \%$ salt solution treatment with $86 \%$ (Table 4, Figure 1). The check cultivars behaved as expected with tolerant cultivars (Mesa Sirsa and Malone) germinating at 36\% and 50\% respectively under $2.0 \%$ salt concentration versus the susceptible cultivars (Rambler and Saranac) germinating at $0 \%$ and $10 \%$ respectively and they were significantly different $(p=0.009)$ (Table 4). A localized cultivar (Barstow) was also used as a check and germination was statistically similar to the other more tolerant cultivars up to the $2.0 \%$ concentration where germination greatly dropped off (Figure 1). IC(50) values also provide a clear indicator of osmotic potential as it inhibits $50 \%$ of viable seed and Salado required the greatest osmotic potentialto limit germination and subsequently the highest germination rate at the $2.0 \%$ level.

Mean germination for all five concentrations was graphed and $2^{\text {nd }}$ order polynomial trendlines applied and summarized (Table 3). Six selected cultivars were graphed at all five salt concentrations to compare $2^{\text {nd }}$ order polynomial regression trendlines for germination potential (Figure 1). Tolerant cultivars (Salado and Malone) showed a resiliency to increasing salinity while susceptible cultivars (Rambler) showed an inability to tolerate increased salinity levels at the germination stage. The ability of a cultivar to germinate and establish under highly saline conditions is clearly quantified in this experiment and selection of the appropriate cultivar is a 
critical decision. As salinity levels increased the differences between cultivars ability to establish became more dramatic. However, this experiment only reflects the germination stage of the plant (critical at the stand establishment level) and may or may not correlate with production potential.

\subsection{Greenhouse Results}

The mean SCR value was $0.914 \pm 0.02$ and ranged from 0.690 (susceptible check AZ88NDC) to 0.984 (tolerant check AZ90NDC ST). Significant differences in SCR values were found between cultivars when subject to analysis of variance $(p=0.004, L S D=0.13)$ (Table 4). Results are indicative of salt stress over time as salt loading occurs and a plant responds physiologically to heightened saline conditions. SCR values are a screening approach that seeks to ascertain the effect of cultivar response to salinity under controlled conditions to provide en masse screening of a large number of cultivars in a timely manner (as opposed to more expensive and time-demanding initial screening in the field where less control of saline conditions can occur and where field conditions may not be repeatable due to changes in climate, soil salinity, irrigation water, pests, etc.). This information can enable plant breeders and researchers to hasten selection for these differences in future experiments and attempt to utilize the trends in developing future salt tolerant cultivars.

Results from this experiment were in line with the NAAIC "Forage Production Under Salt Stress" screening protocol which indicated that SCR values for control cultivars are generally between 0.6 and 0.75 (susceptible cultivar AZ-88NDC had an SCR value of 0.690). This protocol also cautioned against interpretation of SCR values $<0.5$ or $>0.95$, the range of all SCR values from this experiment except for one (tolerant check AZ90NDC ST which was $>0.95$ ) (Smith, 1991). Since the SCR value is a relative value, values $>0.95$ indicate that cultivars are able to produce yields under saline conditions similar to those under non-saline conditions. The importance of this relative value becomes obvious when we compare SCR values to average yields under saline irrigation. In general, cultivars with high production under saline irrigation had higher SCR values with the exception of the tolerant check AZ90NDC ST which was significantly different (lower) than other cultivars ( $p=$ $0.000, L S D=2.61 \mathrm{~g}$ ) (Table 4). This is an important consideration because if only yields from saline irrigation are considered, cultivars that have a higher relative ability to regrow under saline conditions versus non-saline conditions might not be selected for future plant breeding. The relativity of the SCR value allows for the selection of those lines that have high regrowth potential under saline conditions and for further selection for high yield. Observing only yields under saline irrigation may be an important practice for observing current cultivars on the market but may be limiting in the selection and breeding of new, tolerant lines.

\subsection{Field Results}

The three year average fresh forage yield per cutting was $10904 \pm 233 \mathrm{~kg} / \mathrm{ha}$ with a range of 9620 to 12008 $\mathrm{kg} / \mathrm{ha}$ (Table). When fresh forage weights $(\mathrm{kg} / \mathrm{ha})$ were averaged per cut over the three year experiment and submitted to ANOVA significant differences were quantified between cultivars $(p=0.021, L S D=919 \mathrm{~kg} / \mathrm{ha})$ (Table 4). The block effect was shown to be significant $(p=0.0367)$ with the front of the field yielding higher than the back of the field. This indicates potential issues with the level of the field over time and even water movement across the field associated with flood irrigation and emphasizes the importance of proper statistical analysis methods that account for block affects.

Composite soil samples for each field plot from 2007 and 2010, or before and after three years of intense flood irrigation, were compared using a t-test for paired sample means to assess changes in salinity. The average conductivity was $899 \pm 45 \mu \mathrm{mho} / \mathrm{cm}$ in 2007 versus $833 \pm 33 \mu \mathrm{mho} / \mathrm{cm}$ in 2010 . There were no statistical differences between means $(p>0.05$, $t$-statistic $=1.28)$ or no change in conductivity over the three year period. This lack of a change in conductivity or salt loading over time may be attributed to the following: 1) applying water via flood irrigation versus spray irrigation is good salinity management and leaches soluble salts below the root zone, 2) this results in very little salt accumulation at the soil surface or root zone, suggesting that sprinkler irrigation would have been more likely to impose severe salinity conditions.

\subsection{Comparison of Experiments}

Cultivars were evaluated in three different experiments that assessed salt tolerance at different physiological and phenological stages of plant growth and under varying salinity stress environments. Using the rank and percentile function in Microsoft Excel 2010 Data Analysis tool pack for 1.0\% germination, $1.5 \%$ germination, $2.0 \%$ germination, IC(50), average saline yields in the greenhouse, SCR values and field production values we ranked cultivars. These ranks were then used to develop a cumulative rank score that was then ranked again using the rank and percentile function to develop an overall final performance rank (Table 4). Salado was the best performer across experiments indicating higher salt tolerance at various physiological and phenological stages. Ranking should be approached with caution as it may or may not indicate statistical differences between 
cultivars but does provide a means of selection criteria for producers and breeders alike.

Multiple regression was applied to assess correlations between experiments. Fresh field forage yields were used as the dependent variable and the following variables were used as the independent variables (or potential predictors of salt tolerance and performance in the field): Lab IC(50), germination at $0 \%$, germination at $0.5 \%$, germination at $1.0 \%$, germination at $1.5 \%$, germination at $2.0 \%$, SCR value, yield under saline irrigation in the greenhouse and yield under non-saline irrigation in the greenhouse using standardized values. The overall model was significant and highly correlated upon first consideration $\left(p=0.044, R^{2}=0.99\right)$ with the following independent variables having significance $(p<0.05)$ : $\mathrm{Lab} \mathrm{IC}(50)$, germination at $0 \%$, germination at $1.0 \%$, germination at $1.5 \%$, SCR values, yield under saline irrigation in the greenhouse and yield under non-saline irrigation in the greenhouse. Given the issue of multiple comparisons in multiple regression we have to interpret this analyses very cautiously as the likelihood of falsely rejecting the null hypothesis is very high. Thus, we then employed the Bonferroni correction by multiplying all $\mathrm{p}$ values by 10 (9 independent variables and the overall model). The correction renders all $\mathrm{p}$ values greater than 0.05 and we no longer interpret this model as being statistically significant. However, this does not indicate that interactions are not necessarily significant it simply indicates the limitation of multiple regression for complex data sets and the limitation in interpreting outcomes across experiments.

Given the limitations of multiple regression we then chose to employ CCA to further attempt to explain the variation between cultivars and their response to salinity stress. The Monte Carlo test for significance (999 permutations) of the first canonical axis and all canonical axes together was significant $(p<0.05)$ but we interpret this cautiously due to potential redundancy between variables. The first CCA axis explains $49.2 \%$ of the species-environment relation and the second CCA axis explains $19.8 \%$ of the species-environment relation (69.0\% cumulative between the first two CCA axes). We then developed an ordination biplot (Figure 2) to further investigate relationships between tests. The first CCA axis appears to be best explained by field production indicated by the three year average. Five of the top six varieties in terms of yield under field conditions are located on the left side of the diagram (Table 4, Figure 2). The second CCA axis appears to be best explained by germination at the $2 \%$ salt concentration level and IC(50) values (which are negative values or $\mathrm{MPa}$ ). This display of cultivars in ordination space relative to screening experiments can provide a general idea of performance under salinity stress. This method of using ordination is very powerful and may provide an additional method for assessing large numbers of cultivars in the lab or greenhouse. Additional physiological measurements (length of stem, length of cotyledons, etc.) could add power for future investigations.

Cultivars were then displayed in an ordination diagram along the gradients of SCR values or potential regrowth under salt stress (Figure 3) with the Loess smoother applied. This allows us to observe potential performance and compare it to other cultivars relative to their location in the diagram. Four of the top five ranked cultivars are located on the left side of vertical axis while six of the seven on the right side of the vertical axis were ranked in the lower half. The gradient of SCR values appears to increase moving upward along the vertical axis. This attribute plot helps to further explain the second axis of the CCA diagram and performance across experiments. Ordination has provided a more powerful tool for analyzing the complexity of salinity evaluations and variance in cultivar performance associated with genetic variability and varying physiological and phenological stages of response.

\subsection{Conclusions}

Twelve alfalfa cultivars were carried through three primary salt screening procedures. Comparison of screening procedures can be difficult due to the complexity of salinity. Laboratory and greenhouse experiments may not correlate with field experiments and this has been observed in this project in several cases. This is due to the fact that field conditions are extremely difficult to control and standardize as compared to the laboratory or greenhouse. Application of irrigation water at the field scale when applied via flood application methods is especially difficult to standardize and control, and the flooding process - necessary to manage alfalfa in the Trans Pecos region ofwest Texas, likely limited the desired hyper-accumulation of salt in the soil surface in this experiment. Evaluation at the germination stage is absolutely critical in developing cultivars that can establish a stand. This is the key starting point to the identification of salt tolerant germplasm. Development of SCR values is an excellent method to screen large sets of germplasm quickly and get an idea for regrowth potential. Another potential problem in correlating SCR testing and field level performance is the greenhouse methodology removed the requirement for a cultivar to be able to germinate under high salinity levels. This project has reaffirmed the difficulty in correlating different screening procedures for salt tolerance in alfalfa.

The importance of researching, developing and marketing salt tolerant alfalfa cultivars is substantial especially 
when we consider the economic advantages to growers in salt affected regions. Comparing the top three yielding, commercially available cultivars in the field experiment (Salado, SW9720 and AmeriStand 801S) to the predominant local landrace (Barstow Common) an economic advantage becomes apparent. The average dry matter yield per cutting of the top three market-available cultivars from the field project was $3132 \mathrm{~kg} / \mathrm{ha}$ versus Barstow Common at $2721 \mathrm{~kg} / \mathrm{ha}$ (a difference of $411 \mathrm{~kg} / \mathrm{ha}$ per cutting). When we consider the average 2011 price in the Trans Pecos region of Texasat $\$ 254$ per metric ton, the economic advantage per cutting for growers is $\$ 104.60$ or $\$ 697.68$ annually (averaging 6.67 cuttings per year over the three year period). This economic impact is an important factor for growers to consider especially as they look at the cost of establishing or replacing a stand.

Differentiating between survival, establishment and yield under salt stress is also key to the process. This project validates the difficulty in correlating salt tolerance at various physiological and phenological growth stages using laboratory, greenhouse and field scale investigations (Cluff, 1997; McKimmie and Dobrenz, 1987). The germination and SCR evaluation methods continue to be a valuable tool for screening but more powerful statistical methods such as multivariate techniques coupled with finer scale physiological and phenological measurements will enhance our understanding of salinity tolerance. Coupling this with field based experiments will continue to help link expected performance from breeders and scientists with observations from growers. The field portion of this project also confirms two advantages to applying irrigation water via flood rather than sprinkle. Applying it via flood helped to minimize salt loading in the soil solution in the field project. Flood irrigation is also a strategy to avoid water-to-leaf contact in an effort to minimize salt injury that is an issue with spray applications of irrigation water.

\section{References}

Assadian, N. W., \& Miyamoto, S. (1987). Salt effects on alfalfa seedling emergence. Agronomy Journal, 79(4), 710-714. http://dx.doi.org/10.2134/agronj1987.00021962007900040026x

Barnes, D. K., Golen, B. P., \& Baylor, J. E. (1980). Highlights in the USA and Canada. In Alfalfa and Alfalfa Improvement. Number 29 Agronomy Series. Madison, WI: Crop Science Society of America.

Bernstein, L., \& Hayward, H. E. (1957). Physiology of salt tolerance. U.S. Salinity Laboratory, Soil and Water Conservation Research Division, Agricultural Research Service, United States Department of Agriculture, Riverside, CA.

Brown, J. W., \& Hayward, H. E. (1956). Salt tolerance of alfalfa varieties. Journal of Agronomy, 48, 18-20. http://dx.doi.org/10.2134/agronj1956.00021962004800010005x

California Fertilizer Association. (1985). Western Fertilizer Handbook 7th Edition. California Fertilizer Assoc., Soil Improvement Committee. pp. 186-187. Sacramento, CA.

Carlson, J. R., Ditterline, J. M., Martin, J. M., Sands, D. C., \& Lund, R. E. (1983). Alfalfa seed germination in

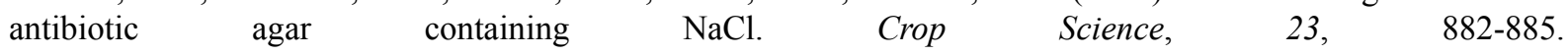
http://dx.doi.org/10.2135/cropsci1983.0011183X002300050016x

Chinnusamy, V., Jagendorf, A., \& Zhu, J. K. (2005). Understanding and improving salt tolerance in plants. Crop Science, 45, 437-448. http://dx.doi.org/10.2135/cropsci2005.0437

Cluff, G. (1997). Breeding for "true" salt tolerance. In Abstracts, Western Alfalfa Improvement Conf. Proc. Davis, CA. 27-28 Jun. 1997. Davis, CA.

Croughan, T. P., Stavarek, S. J., \& Rains, D. W. (1978). Selection of $\mathrm{NaCl}$ tolerant line of cultured alfalfa cells. Crop Science, 18, 959-963. http://dx.doi.org/10.2135/cropsci1978.0011183X001800060012x

Der, G., \& Everitt, B. S. (2007). Basic statistics using SAS Enterprise Guide a primer. SAS Publishing. Cary, NC, USA.

Der, G., \& Everitt, B. S. (2008). A handbook of statistical analyses using SAS, third edition. SAS Publishing. Cary, NC, USA.

Fipps, G. (2003). Irrigation water quality standards and salinity management B-1667. Texas AgriLife Extension Service. Texas A\&M Univ. Publication. College Station, TX. [Online] Available: http://soiltesting.tamu.edu/publications/B-1667.pdf

Green, C. J. (1999). Forage production under saline conditions. In Proc. Animal Production in the Gulf region: implications for salt-tolerant plants. 27 Nov. 1999. UAE Univ. Al-Ain, United Arab Emirates.

Johnson, L. D. (1989). Three methods of evaluating salt tolerance in alfalfa. Thesis. New Mexico State 
University. Las Cruces, NM.

Hanson, B. R., Bali, K. M., \& Sanden, B. L. (2008). Irrigating alfalfa in arid regions. In Irrigated alfalfa management for mediterranean and desert zones, University of California - Davis. [Online] Available: http://alfalfa.ucdavis.edu/IrrigatedAlfalfa/

Havlin, J. L., Beaton, J. D., Tisdale, S. L., \& Nelson, W. L. (1999). Soil fertility and fertilizers 6th Edition: An introduction to nutrient management. Prentice Hall, Inc. Upper Saddle River, NJ 07458.

Hefny, M. M., \& Dolinksi, R. (1998). Evaluation of different alfalfa (Medicago sativa L. Sensu lato) varieties under different concentrations of $\mathrm{NaCl}$ during germination stage. In Abstracts, North American Alfalfa Improvement Conference Proceedings. Bozeman, $\quad$ MT. $\quad$ [Online] http://www.naaic.org/Publications/1998Proc/abstracts/Hefny.html

Lauchli, A. (1984). Salinity Tolerance in Plants and Strategies for Crop Improvement: Chapter 9 Salt Exclusion. In An Adaptation of Legumes for Crops and Pastures Under Saline Conditions (pp. 171-187) John Wiley and Sons.

Li, G., \& Zhang, Y. (2004). Alfalfa water requirement and water use efficiency. In Abstracts, North American Alfalfa Improvement Conference Proceedings, Quebec City, Canada. [Online] http://www.naaic.org/Meetings/National/2004NAAIC\&TC/2004abstracts/gli.pdf

Lindsey, K. E., Neeb, C. W., \& Taylor, C. A. (1970). Alfalfa seed production in west Texas. Texas Agricultural Extension Service. Texas A\&M Univ. Publication, Pecos, TX.

Longenecker, D. E., \& Lyerly, P. J. (1974). Control of soluble salts in farming and gardening: B-876. Texas Agricultural Experiment Station. Texas A\&M Univ. Publication. College Station, TX.

Maas, E. V., \& Hoffman, G. J. (1977). Crop salt tolerance, current assessment. Journal of Irrigationand Drainage, 115.

Maas, E. V. (1987). Salt tolerance of plants. In CRC Handbook of Plant Science in Agriculture. Vol. 2 (pp. 57-75). Boca Raton, FL.

McKimmie, T., \& Dobrenz, A. K. (1987). A method for evaluation of salt tolerance during germination, emergence and seedling establishment. Agronomy Journal, 79, 943-945. http://dx.doi.org/10.2134/agronj1987.00021962007900050038x

Miyamoto, S., Moore, J., \& Stichler, C. (1984). Saline water irrigation in far west Texas. In Proceedings of the Specialty Conference of the Irrigation and Drainage Division of the American Society of Civil Engineers. Flagstaff, AZ.

Miyamoto, S. (1988). Sampling irrigated soils for salinity appraisal: B-1570. Texas Agricultural Experiment Station. Texas A\&M Univ. Publication. El Paso, TX.

Munns, R. (2005). Response of crops to salinity. In Abstracts, International Salinity Forum Proceedings, pp. 339, Riverside, CA. 25-27 Apr. 2005. Riverside, CA.

Munns, R. (2011). The impact of salinity stress. In The Environmental and Physiological Nature of Salinity. [Online] http://www.plantstress.com/Articles/salinity_i/salinity_i.htm

Palmer, M. (2012). Ordination methods for ecologists: basic statistical concepts. Oklahoma State Univ. Stillwater, OK. [Online] http://ordination.okstate.edu/STATS.htm.

Provin, T. L., \& Pitt, J. L. (2001). Managing soil salinity. Texas AgriLife Extension Service publication E-60. Texas A\&M Univ. Publication. College Station, TX. [Online] http://soiltesting.tamu.edu/publications/E-60.pdf

Provin, T. L., \& Pitt, J. L. (2002). Description of water analysis parameters SCS-2002-10. Texas AgriLife Extension Service publication. Texas A\&M Univ. Publication. College Station, TX. [Online] http://soiltesting.tamu.edu/publications/SCS-2002-10.pdf

Rawlins, S. L. (1979). Irrigation to miminize salt problems. In Abstracts, $9^{\text {th }}$ California Alfalfa Symposium Proceedings, Fresno, CA. pp. 68-71. [Online] http://alfalfa.ucdavis.edu/+symposium/proceedings/2005-237.pdf

Rhoades, J. D., \& Loveday, J. (1990). Salinity in irrigated agriculture. Agronomy Journal, 30, 1089-1142.

Rumbaugh, M. D. (1991). Salt tolerance of germinating alfalfa seeds. In North American Alfalfa Improvement Conference Standard Tests to Characterize Alfalfa Cultivars. [Online] http://www.naaic.org/stdtests/saltseeds.htm 
Safarenjad, A., Collin, H. A., Bruce, K. D., \& McNeilly, T. (1996). Characterization of alfalfa (Medicago sativa L.) following in vitro selection for salt tolerance. Adaptation in Plant Breeding, 92, 55-61.

Smith, S. E. (1991). Forage production under salt stress. In North American Alfalfa Improvement Conference Standard Tests to Characterize Alfalfa Cultivars. [Online] http://www.naaic.org/stdtests/salt.pdf

Smith, S. E. (1998). Evaluating salt tolerance: some experiences with nondormantalfalfa. In Abstracts, North American Alfalfa Improvement Conference Proceedings 1998. Bozeman, MT.

Smith, S. E., \& Dobrenz, A. K. (1987). Breeding for improved salt tolerance in alfalfa. In Abstracts $17^{\text {th }}$ Californica/Arizona Alfalfa Symposbium Proceedings, El Centro, CA. [Online] http://ucanr.org/alfa_symp/1987/87-01.pdf

Smith, M. K., \& McComb, J. A. (1981). Use of callus cultures to detect $\mathrm{NaCl}$ tolerance in cultivars of three species of pasture legumes. Australian Journal of Plant Physiology, 8, 437-442. http://dx.doi.org/10.1071/PP9810437

ter Braak, C. J. F., \& P. Šmilauer. (2002). CANOCO reference manual and CanoDraw for windows user's guide: software for canonical community ordination (version 4.5). Ithaca, NY, USA: Microcomputer Power. p.500.

Vaughan, L. S., MacAdam, J. W., Smith, S. E., \& Dudley, L. M. (2002). Root growth and yield of differing alfalfa rooting populations under increasing salinity and zero leaching. Crop Science, 42, 2064-2071. http://dx.doi.org/10.2135/cropsci2002.2064

Waskom, R. M., Bauder, T. A., Davis, J. G., \& Cardon, G. F. (2007). Diagnosing saline and sodic soil problems No. 0.521. Colorado State Univ. Publication, Fort Collins, CO. [Online] http://www.ext.colostate.edu/pubs/crops/00521.html

Yuegao, H., \& Cash, D. (2009). Global status and development trends of alfalfa. In Alfalfa management guide for Ningxia. United Nations Food and Agriculture Organization. Beining, China. [Online] http://www.fao.org/ag/AGP/AGPC/doc/ningxia_guide/alfalfa_guide_ningxia.pdf

Table 1. Summary of all alfalfa cultivars evaluated in this project including name, reference code, seed source or company and fall dormancy rating

\begin{tabular}{cccc}
\hline Code & Cultivar & Source/Company & Fall Dormancy Rating \\
\hline A801 & AmeriStand 801S & America's Alfalfa & 8 \\
A802 & AmeriStand 802 & America's Alfalfa & 8 \\
AZ88 & AZ88NDC & University of Arizona & 8 \\
AZ90 & AZ90NDC ST & University of Arizona & 1 \\
Bars & Barstow Common & local landrace & 9 \\
CW39 & CW39060 & Cal/West Seed & Unknown \\
CW59 & CW59086 & Cal/West Seed & 9 \\
FG91 & FG91T005GT & Forage Genetics & 9 \\
FGR1 & FGR105BD101 & Forage Genetics & 9 \\
Malo & Malone & USDA ARS NPGS & 10 \\
Mesa & Mesa Sirsa & USDA ARS NPGS & 7 \\
P58 & P58N57 & Pioneer & Unknown \\
Ramb & Rambler & USDA ARS NPGS & 8 \\
Sala & Salado & America's Alfalfa & Unknown \\
Sara & Saranac & USDA ARS NPGS & 9 \\
SW97 & SW9720 & S\&W Seed & Unknown \\
TS00 & TS0002 & Target Seed & 9 \\
TS80 & TS8028 & Target Seed & 10 \\
\hline STh & & 8 \\
\hline
\end{tabular}

${ }^{1}$ Dr. Steve Smith Plant Science Department

${ }^{2}$ Local landrace seed source obtained from local farm

${ }^{3}$ National Plant Germplasm System 
Table 2. Summary of soil and water quality parameters for field, lab and greenhouse methods

\begin{tabular}{ccccc}
\hline Quality Parameter & Field & Field & Lab & Greenhouse \\
\hline Type & Soil & Water & Water & Water \\
Source & Hoban silty clay loam & Pecos River alluvium & NAAIC ${ }^{3}$ & NAAIC $^{3}$ \\
Total Dissolved Salts & $2131 \mathrm{ppm}$ & $2950 \mathrm{ppm}$ & $0-20000 \mathrm{ppm}$ & 0 or $3840 \mathrm{ppm}$ \\
Electrical Conductivity & $3.33 \mathrm{dS} / \mathrm{m}$ & $4.06 \mathrm{dS} / \mathrm{m}$ & $0-31.25 \mathrm{dS} / \mathrm{m}$ & $6.00 \mathrm{dS} / \mathrm{m}$ \\
pH & 8.9 & 7.1 & & \\
Sodium Absorption Ratio & 13.6 & 11.7 & \\
sodium (Na) & $1491 \mathrm{ppm}$ & $702 \mathrm{ppm}$ & \\
Classification/Rating & Sodic Soil ${ }^{1}$ & Class 5: Unsuitable & \\
\hline${ }^{1}$ Sodic Soil if: EC $>$ 4.0dS/m, $\mathrm{pH}>8.5$, SAR $>13$ (Waskom et al 2007; Havlin et al 1999) \\
${ }^{2}$ Class 5: Unsuitable if: TDS $>$ 2100 ppm (Fipps 2003; Provin and Pitt 2002) \\
${ }^{3}$ Water solution prepared according to NAAIC protocols \\
\hline
\end{tabular}

Table 3. Summary of alfalfa cultivars germination and $2^{\text {nd }}$ order polynomial equations and $\mathrm{R}^{2}$ values

\begin{tabular}{ccc}
\hline Cultivar & Slope equation for 2nd order polynomial & $\mathbf{R}^{\mathbf{2}}$ \\
\hline A801 & $\mathrm{y}=-36 \mathrm{x}^{2}+44.4 \mathrm{x}+94$ & 0.9369 \\
A802 & $\mathrm{y}=-29.714 \mathrm{x}^{2}+34.629 \mathrm{x}+95.143$ & 0.9543 \\
Bars & $\mathrm{y}=-46.286 \mathrm{x}^{2}+53.771 \mathrm{x}+88.857$ & 0.9542 \\
CW39 & $\mathrm{y}=-36.571 \mathrm{x}^{2}+45.943 \mathrm{x}+91.314$ & 0.9289 \\
CW59 & $\mathrm{y}=-37.143 \mathrm{x}^{2}+49.086 \mathrm{x}+91.029$ & 0.8791 \\
FG91 & $\mathrm{y}=-42.286 \mathrm{x}^{2}+47.771 \mathrm{x}+87.657$ & 0.9390 \\
FGR1 & $\mathrm{y}=-29.143 \mathrm{x}^{2}+35.486 \mathrm{x}+86.229$ & 0.9152 \\
Malo & $\mathrm{y}=-20 \mathrm{x}^{2}+22.8 \mathrm{x}+84.4$ & 0.9971 \\
Mesa & $\mathrm{y}=-26.286 \mathrm{x}^{2}+26.171 \mathrm{x}+91.657$ & 0.9701 \\
P58N & $\mathrm{y}=-34.286 \mathrm{x}^{2}+34.971 \mathrm{x}+96.857$ & 0.9697 \\
Ramb & $\mathrm{y}=14.286 \mathrm{x}^{2}-76.171 \mathrm{x}+90.743$ & 0.9352 \\
Sala & $\mathrm{y}=-2.2857 \mathrm{x}^{2}-1.8286 \mathrm{x}+96.457$ & 0.5666 \\
Sara & $\mathrm{y}=-37.714 \mathrm{x}^{2}+41.829 \mathrm{x}+84.343$ & 0.8897 \\
SW97 & $\mathrm{y}=-35.429 \mathrm{x}^{2}+43.657 \mathrm{x}+93.886$ & 0.8561 \\
TS00 & $\mathrm{y}=-24.571 \mathrm{x}^{2}+25.543 \mathrm{x}+79.314$ & 0.7297 \\
TS80 & $\mathrm{y}=-21.714 \mathrm{x}^{2}+23.429 \mathrm{x}+81.943$ & 0.8981 \\
\hline
\end{tabular}


Table 4. Summary comparison of alfalfa (Medicago sativa) cultivars across three experiments assessing germination under increasing levels of salt tolerance in the lab, greenhouse regrowth potential under non-saline and saline irrigation and field production at a saline field site in Pecos, TX, USA

\begin{tabular}{|c|c|c|c|c|c|c|c|c|}
\hline & \multicolumn{4}{|c|}{ LABORATORY } & \multicolumn{2}{|c|}{ GREENHOUSE } & \multirow{2}{*}{$\begin{array}{c}\text { FIELD } \\
\text { Three year } \\
\text { fresh forage } \\
\text { average per } \\
\text { cut }\end{array}$} & \\
\hline & $\begin{array}{l}\text { Percent } \\
\text { salinity }\end{array}$ & $\begin{array}{c}\text { erminatio } \\
2.0 \%)\end{array}$ & $\begin{array}{l}\text { at three } \\
1.5 \% \&\end{array}$ & $\begin{array}{c}I C \\
(50)\end{array}$ & $\begin{array}{c}\text { Average } \\
\text { saline yields }\end{array}$ & $\begin{array}{l}\text { Salt control } \\
\text { ratio }(S C R)\end{array}$ & & \\
\hline Cultivar & $1.0 \%$ & $1.5 \%$ & $2.0 \%$ & MPa & grams & SCR value & $\mathrm{kg} / \mathrm{ha}$ & $\begin{array}{l}\text { Final } \\
\text { rank }\end{array}$ \\
\hline Sala & $98^{\mathrm{a}}$ & $82^{\mathrm{ab}}$ & $86^{\mathrm{a}}$ & -3.40 & $2.87^{\mathrm{ab}}$ & $0.949^{\mathrm{a}}$ & $11534^{\mathrm{abc}}$ & 1 \\
\hline SW97 & $98^{\mathrm{a}}$ & $96^{\mathrm{a}}$ & $32^{\text {bcde }}$ & -1.03 & $2.88^{\mathrm{a}}$ & $0.901^{\mathrm{abc}}$ & $12008^{\mathrm{a}}$ & 2 \\
\hline CW59 & $98^{\mathrm{a}}$ & $96^{\mathrm{a}}$ & $34^{\text {bcd }}$ & -1.07 & $2.73^{\mathrm{abc}}$ & $0.805^{\text {bcd }}$ & $11312^{\mathrm{abc}}$ & 3 \\
\hline A801 & $100^{\mathrm{a}}$ & $90^{\mathrm{ab}}$ & $34^{\mathrm{bcd}}$ & -1.02 & $2.97^{\mathrm{abc}}$ & $0.792^{\text {cd }}$ & $11668^{\mathrm{ab}}$ & 4 \\
\hline A802 & $98^{\mathrm{a}}$ & $88^{\mathrm{ab}}$ & $42^{\mathrm{bc}}$ & -1.10 & $2.60^{\mathrm{bcd}}$ & $0.761^{\mathrm{d}}$ & $11944^{\mathrm{a}}$ & 5 \\
\hline P58N & $96^{\mathrm{a}}$ & $80^{\mathrm{ab}}$ & $26^{\text {bcde }}$ & -0.86 & $2.89^{\mathrm{a}}$ & $0.932^{\mathrm{ab}}$ & $9982^{\text {cd }}$ & ${ }^{t} 6$ \\
\hline CW39 & $100^{\mathrm{a}}$ & $88^{\mathrm{ab}}$ & $32^{\text {bcde }}$ & -0.99 & $2.59^{\mathrm{bcd}}$ & $0.744^{\mathrm{d}}$ & $10794^{\mathrm{abcd}}$ & ${ }^{\mathrm{t}} 6$ \\
\hline FGR1 & $90^{\mathrm{a}}$ & $84^{\mathrm{ab}}$ & $36^{\text {bcd }}$ & -1.01 & $2.56^{\mathrm{cd}}$ & $0.798^{\mathrm{cd}}$ & $10962^{\mathrm{abcd}}$ & 8 \\
\hline TS80 & $84^{\mathrm{a}}$ & $76^{\mathrm{b}}$ & $38^{\text {bcd }}$ & -0.97 & $2.67^{\mathrm{abcd}}$ & $0.913^{\mathrm{abc}}$ & $10063^{\mathrm{cd}}$ & 9 \\
\hline TS00 & $82^{\mathrm{a}}$ & $78^{\mathrm{ab}}$ & $24^{\text {bcde }}$ & -0.79 & $2.61^{\mathrm{bcd}}$ & $0.804^{\text {bcd }}$ & $9620^{\mathrm{d}}$ & ${ }^{\mathrm{t}} 10$ \\
\hline FG91 & $88^{\mathrm{a}}$ & $78^{\mathrm{ab}}$ & $8^{\mathrm{de}}$ & -0.72 & $2.58^{\mathrm{bcd}}$ & $0.800^{\mathrm{cd}}$ & $10771^{\mathrm{abcd}}$ & ${ }^{\mathrm{t}} 10$ \\
\hline Bars & $96^{\mathrm{a}}$ & $76^{\mathrm{ab}}$ & $6^{\mathrm{de}}$ & -0.72 & $2.46^{\mathrm{d}}$ & $0.812^{\mathrm{bcd}}$ & $10197^{\mathrm{bcd}}$ & ${ }^{\mathrm{t}} 10$ \\
\hline$+A \mathbf{Z 9 0}$ & $\mathrm{NE}$ & $\mathrm{NE}$ & $\mathrm{NE}$ & $\mathrm{NE}$ & $2.48^{\mathrm{d}}$ & $0.984^{\mathrm{a}}$ & $\mathrm{NE}$ & \\
\hline †Mesa & $90^{\mathrm{a}}$ & $78^{\mathrm{ab}}$ & $36^{\mathrm{bcd}}$ & -0.94 & $\mathrm{NE}$ & $\mathrm{NE}$ & $\mathrm{NE}$ & \\
\hline †Malo & $86^{\mathrm{a}}$ & $74^{\mathrm{b}}$ & $50^{\mathrm{b}}$ & -1.17 & $\mathrm{NE}$ & $\mathrm{NE}$ & $\mathrm{NE}$ & \\
\hline f AZ88 & $\mathrm{NE}$ & $\mathrm{NE}$ & $\mathrm{NE}$ & $\mathrm{NE}$ & $1.836^{\mathrm{e}}$ & $0.690^{\mathrm{d}}$ & $\mathrm{NE}$ & \\
\hline * Sara & $78^{\mathrm{a}}$ & $80^{\mathrm{ab}}$ & $10^{\text {cde }}$ & -0.71 & $\mathrm{NE}$ & $\mathrm{NE}$ & $\mathrm{NE}$ & \\
\hline * Ramb & $22^{\mathrm{b}}$ & $2^{\mathrm{c}}$ & $0^{\mathrm{e}}$ & -0.31 & $\mathrm{NE}$ & $\mathrm{NE}$ & $\mathrm{NE}$ & \\
\hline Mean \pm SE & $88 \pm 4.7$ & $78 \pm 5.3$ & $31 \pm 5.1$ & $\mathrm{NE}$ & $2.607 \pm 0.06$ & $0.914 \pm 0.02$ & $10904 \pm 233$ & \\
\hline P-value & 0.005 & 0.000 & 0.009 & $\mathrm{NE}$ & 0.000 & 0.004 & 0.021 & \\
\hline LSD (0.05) & 23 & 22 & 33 & $\mathrm{NE}$ & 0.250 & 0.132 & 919 & \\
\hline
\end{tabular}

Means within columns followed by the same letter are not different according to Fisher's protected Least significant differences (LSD) at the $5 \%$ level of significance $(\alpha=0.05)$.

$\mathrm{NE}=$ Indicates a check cultivar 'Not Evaluated' in that experiment or for significance

$\mathrm{SE}=$ Standard Error

$\dagger$ Tolerant check cultivar; $₫$ Non-tolerant check cultivar; ${ }^{\mathrm{t}}$ tie 


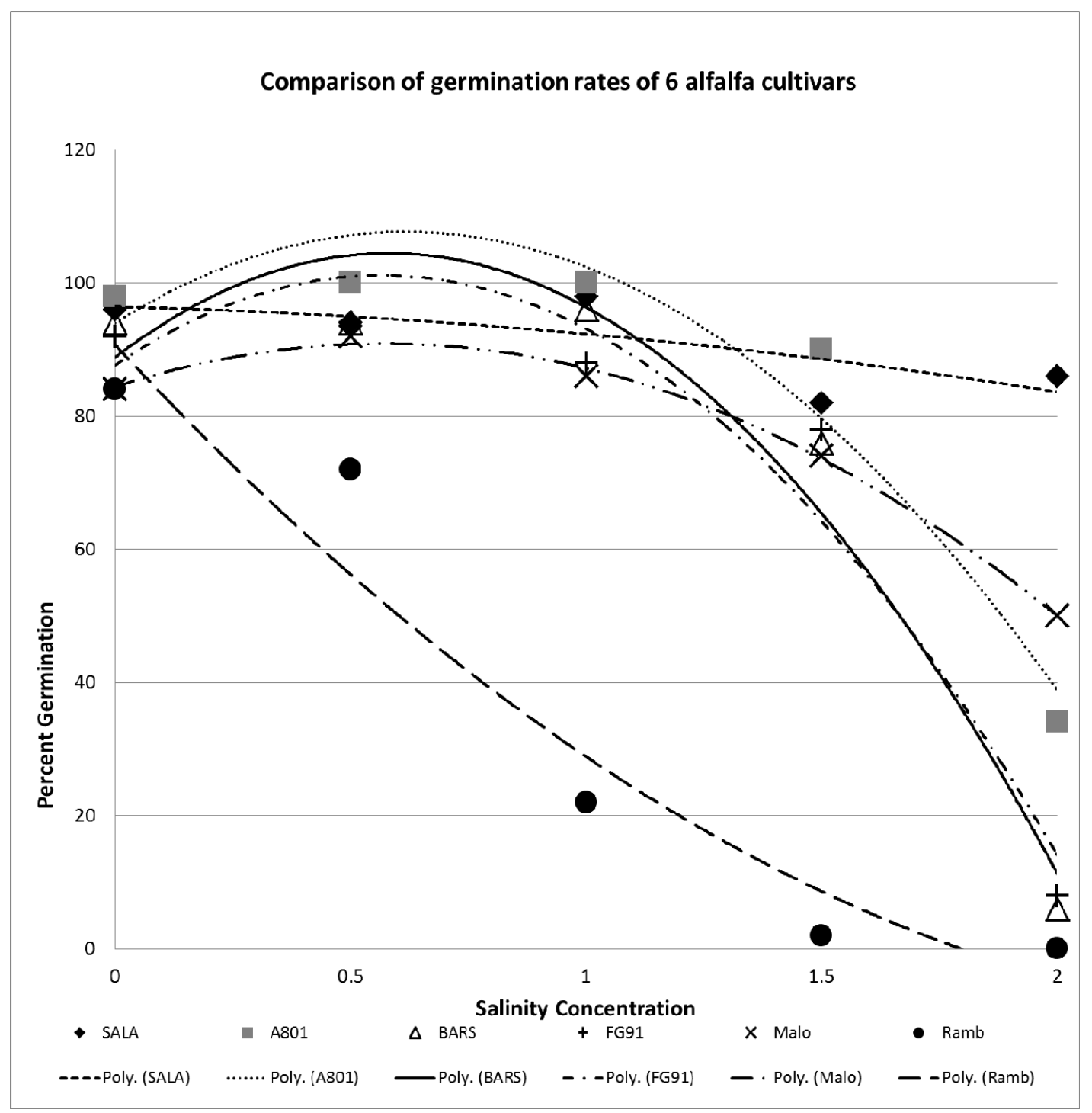

Figure 1. Comparison of germination rates of 6 selected alfalfa cultivars, under 5 salinity concentrations (\%) with a $2^{\text {nd }}$ order polynomial trendline applied 


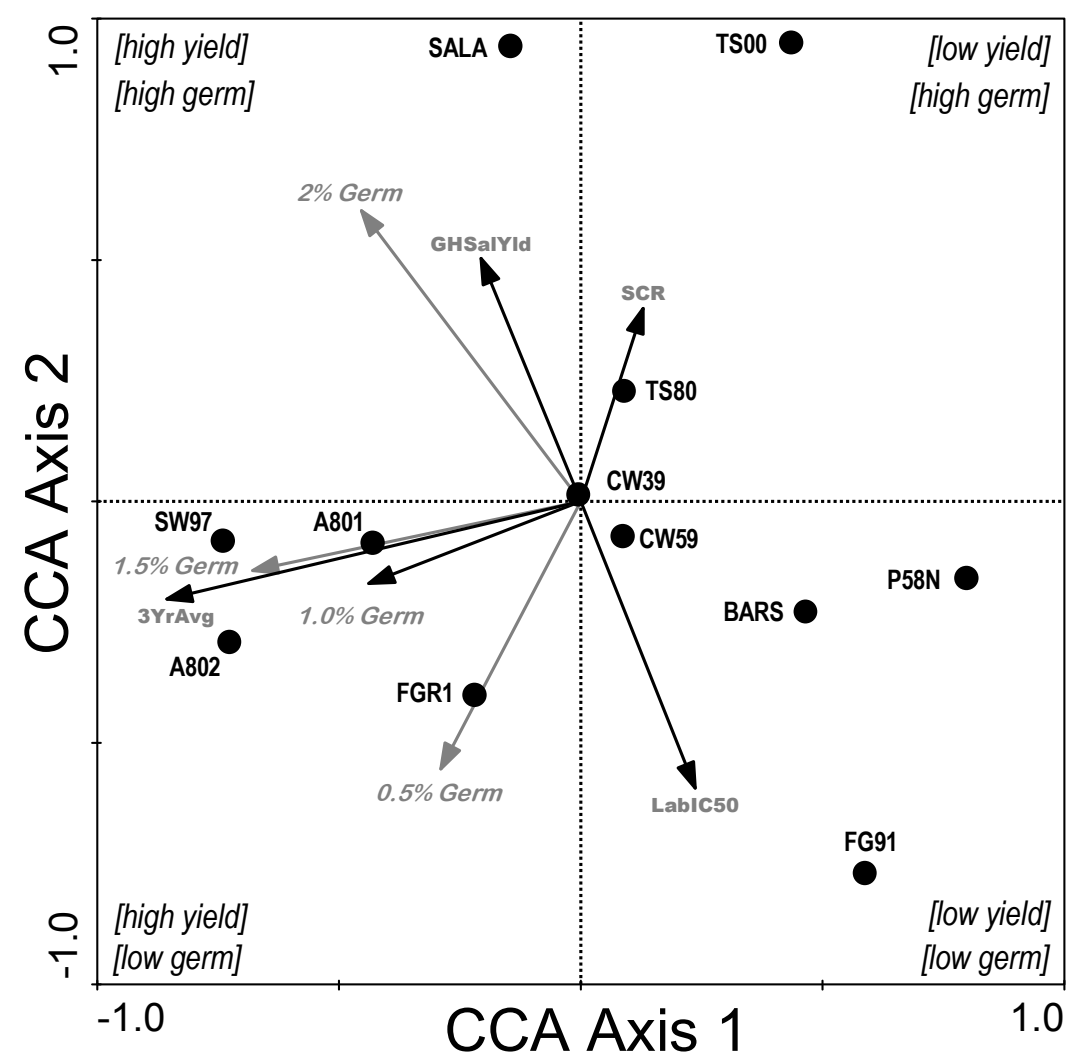

Figure 2. Canonical correspondence analysis (CCA) ordination bipolot displaying alfalfa cultivars (yields) and explanatory variables $(0.5 \%$ germination rate, $1.0 \%$ germination rate, $1.5 \%$ germination, $2.0 \%$ germination rate, lab IC(50) value, salt control ratio (SCR) and 3 year production average. The display of cultivars in ordination space relative to screening experiments can provide a general idea of performance under saline conditions

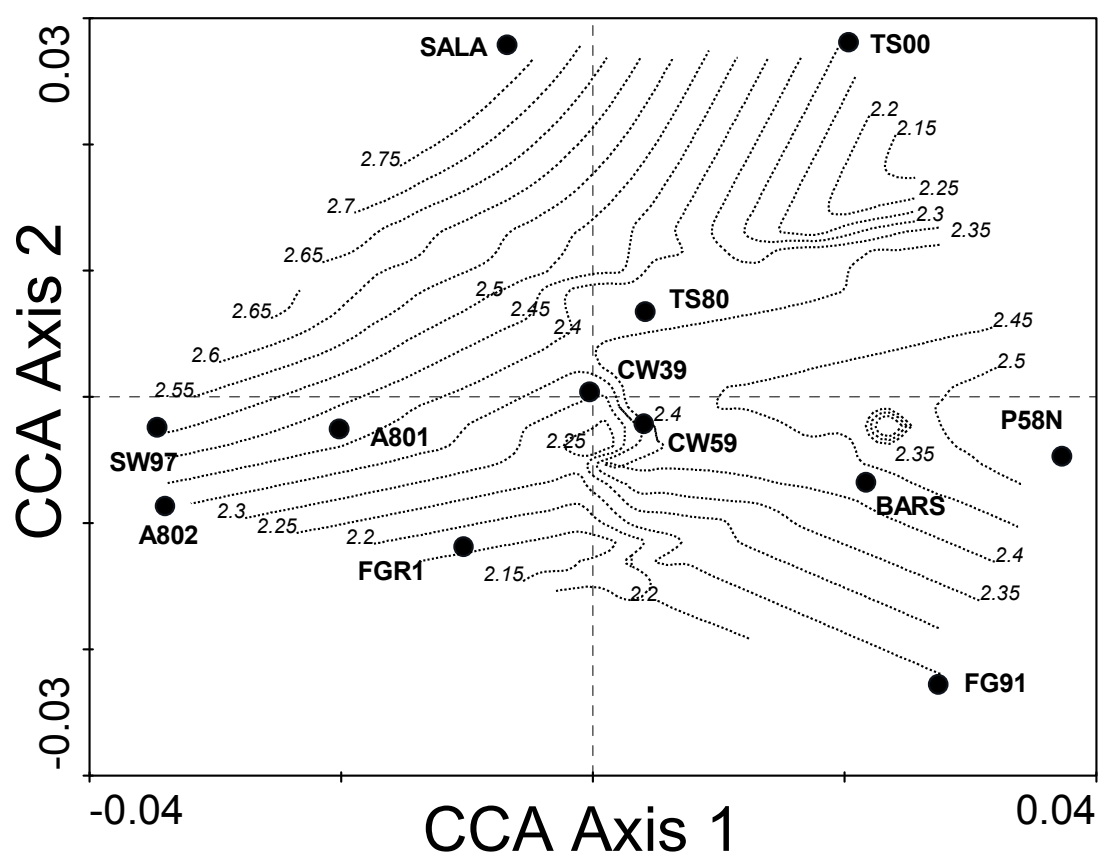

Figure 3. Canonical correspondence analysis (CCA) ordination bipolot using the Loess smoother model to display alfalfa cultivar yield potential along the gradient of greenhouse salt control ratio (SCR) values. SCR values are generally increasing moving up along the second CCA axis 